\title{
TRIBOLOGICAL BEHAVIOR OF COARSE RAPESEED OIL TESTED ON FOUR BALL TESTER
}

\author{
Traian Florian IONESCU, Dionis GUGLEA, Constantin GEORGESCU, \\ Petrica ALEXANDRU, Lorena DELEANU \\ "Dunărea de Jos" University of Galati, Faculty of Faculty of Engineering, \\ 47 Domneasca, RO-800008, Galati, Romania \\ * Corresponding author: traian.ionescu@ugal.ro
}

\begin{abstract}
This paper presents the influence of load and sliding velocity on several tribological parameters like friction coefficient and wear rate of the wear scar diameter of the balls used in a four-ball test, when using rapeseed oil as lubricants. The test parameters for were: loading force $100 \mathrm{~N}, 200 \mathrm{~N}$ and $300 \mathrm{~N}( \pm 5 \%)$, sliding speed of $0.38 \mathrm{~m} / \mathrm{s}, 0.53 \mathrm{~m} / \mathrm{s}$ and $0.69 \mathrm{~m} / \mathrm{s}$, corresponding to the spindle speeds of the four-ball machine $1000 \mathrm{rpm}, 1400 \mathrm{rpm}$ and $1800 \mathrm{rpm}$ ( $\pm 6 \mathrm{rpm}$ ), respectively, test time - 60 minutes $( \pm 1 \%)$. The test balls are lime polished, made of chrome alloyed steel balls (EN31), having 12.7 $\pm 0.0005 \mathrm{~mm}$ in diameter, with $805 \mathrm{~N} / \mathrm{mm} 2$ hardness VHN, as delivered by $S K F$. The sample oil volume required for a test was $8 \mathrm{ml} \pm 1 \mathrm{ml}$. A general view of the results on friction coefficient reveals that this vegetal oil could be used in application with mild regime as concerning the load and speed.
\end{abstract}

Keywords: coarse rapeseed oil, four-ball test, friction coefficient, wear rate of wear scar diameter

\section{INTRODUCTION}

Biodegradability, good lubricating properties and low production costs, are the reasons to consider the plant oils a good alternative as reference to replace the petroleum-based oils that have limited resources. The based plant oils are very attractive as alternative lubricant source. Long chain oils indicate low friction and low wear compared to oils with short chains. Oils containing saturated compounds have better oxidation stability at high temperature and pressure compared to oils containing unsaturated compounds. Free fatty acids have a high degree of polarity and will react lightly with metallic surfaces, forming an adsorption film. Table 1 presents typical fat acid concentration for vegetal oils [1].

One of the most important vegetal oil used as a lubricant or biodiesel is the rapeseed oil extracted from seeds of different varieties, containing 59-61\% oleic acid. In traditional rape varieties, the content in oleic acid is only $21 \%$, predominantly monounsaturated erucic acid, but not recommended for human consumption and biodiesel, but with many applications in industry [2].

Rape varieties and hybrids with high oleic acid content and low erucic acid content are the result of genetic progression due to the discovery of natural mutations.

Canadian specialists consider the current rape, a genetically engineered plant, by conventional methods. To distinguish it from the traditional rapeseed, the term canola, derived from "Canadian oil low erucic acid" [3] was introduced.

Rape is the world's third largest source of vegetal oil, after palm oil and soybean oil [4]. Rapeseed oil has a low content of saturated fatty acids (5-10\%), a high content of mono-unsaturated fatty acids, being a rich source of antioxidant compounds, such as polyphenols, tocopherols, $\beta$-carotene, lutein, phytosterols, etc. [5], [6].

The physicochemical characteristics of rapeseed oil are: peroxide index $=10 \mathrm{mmol}$ of active oxygen $/ \mathrm{kg}$, mass fraction of water and volatile substances $=0.15-0.2 \%$, relative density at $20{ }^{\circ} \mathrm{C}=$ 0.914-0.920; refractive index $=1.465-1.467$; saponification index $=182-193 \mathrm{mg} \mathrm{KOH} / \mathrm{g}$ oil, iodine index $=105-126 \mathrm{~g} \mathrm{I} / 100 \mathrm{~g}$ [1].

Ruggiero et al [7] investigated physico-chemical and tribological performances of three vegetal oils in the lubricating contact pair AISI E52100 steel, sliding against X210Cr12 steel. Fatty 
Table 1. Typical fat acid concentration for vegetal oils [1]

\begin{tabular}{|c|c|c|c|c|c|c|}
\hline Fat acid, [\%] & Soybean oil & $\begin{array}{c}\text { Rapeseed } \\
\text { oil }\end{array}$ & Corn oil & Olive oil & $\begin{array}{c}\text { Sun-flower } \\
\text { oil }\end{array}$ & Palm oil \\
\hline Lauric acid (C12:0) & $<0.1$ & - & $<0.3$ & - & $<0.1$ & $45.0-55.0$ \\
\hline Myristic acid (C14:0) & $<0.2$ & $<0.2$ & $<0.3$ & $<0.05$ & $<0.2$ & $14.0-18.0$ \\
\hline Palmitic acid (C16:0) & $8.0-13.5$ & $2.5-7.0$ & $8.6-16.5$ & $7.5-20.0$ & $5.0-7.6$ & $6.5-10.0$ \\
\hline Palmitoleic acid (C16:1) & $<0.2$ & $<0.6$ & $<0.5$ & $0.3-3.5$ & $<0.3$ & $<0.2$ \\
\hline Stearic acid (C18:0) & $2.0-5.4$ & $0.8-3.0$ & $<3.3$ & $0.5-5.0$ & $2.7-6.5$ & $1.0-3.0$ \\
\hline Oleic acid (C18:1) & $17.0-30.0$ & $51.0-70.0$ & $20.0-42.0$ & $55.0-83.0$ & $14.0-39.4$ & $12.0-19.0$ \\
\hline Linoleic acid (C18:2) & $48.0-59.0$ & $15.0-30.0$ & $34.0-65.6$ & $3.5-21.0$ & $48.3-74.0$ & $1.0-3.5$ \\
\hline Linolenic acid C18:3 & $4.5-11.0$ & $5.0-14.0$ & $<2.0$ & - & $<0.3$ & $<0.2$ \\
\hline Arachidic acid (C20:0) & $0.1-0.6$ & $0.2-1.2$ & $0.3-1.0$ & $<0.6$ & $0.1-0.5$ & $<0.2$ \\
\hline Ecosenoic acid (C20:1) & $<0.5$ & $0.1-4.3$ & $0.2-0.6$ & $<0.4$ & $<0.3$ & $<0.2$ \\
\hline Behenic acid (C22:0) & $<0.7$ & $<0.6$ & $<0.5$ & $<0.2$ & $0.3-1.5$ & $<0.2$ \\
\hline Erucic acid (C22:1) & $<0.3$ & $<2$ & $<0.3$ & - & $<0.3$ & - \\
\hline Docosadienoic acid (C22:2) & - & 0.1 & - & - & $<0.3$ & - \\
\hline Lignoceric acid (C24:0) & $<0.5$ & $<0.3$ & $<0.5$ & $<0.2$ & $<0.5$ & - \\
\hline Nervonic acid (C24:1) & - & $<0.4$ & - & 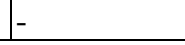 & & - \\
\hline
\end{tabular}

Acid Methyl Ester (FAME), hydrotreated vegetal oil (HVO) from raw rapeseed oil and raw Jatropha curcas L. oil (JCL). The oils were analyzed for their chemical and physical properties such as viscosity, density flash point and TAN. Tests were carried out using ball-on-flat reciprocating tribotester for several frequencies and loads. The oils exhibited good physicochemical properties and could be favorably used as lubricant feedstock in industrial application. The friction coefficient in all tests, for HVO, stays in the range of $0.14-0.17$, in the range of $0.11-0.14$ for the Rapeseed Methyl Ester oil (RME) and in the range of $0.11-0.13$ for JCL that showed the lowest $\mathrm{CoF}$ among the three oils examined, followed by RME and HVO. Whereas, spheres lubricated with HVO underwent to the lowest wear but presented the highest roughness.

$\mathrm{Gu}$ et al. [8] obtained a wear scar diameter of 0.66 $\mathrm{mm}$ when testing rapeseed oil on a four-ball machine, at $392 \mathrm{~N}$ and $1200 \mathrm{rpm}$, for $60 \mathrm{~min}$, using balls made of $\mathrm{GCr} 15$ steel, with a diameter of $12.7 \mathrm{~mm}$ and a hardness of HRC 59-61.

Li and Ren [9] did tests on four ball machine, using rapeseed oil as basic oil for additivation, under loads $(98 \mathrm{~N}, 196 \mathrm{~N}, 294 \mathrm{~N}, 392 \mathrm{~N}, 490 \mathrm{~N})$ with a rotating speed of $1450 \mathrm{rpm}$ for a time duration of 30 min at room temperature. The maximum nonseizure loads was reported at $509.5 \mathrm{~N}$ for the rapeseed oil, this parameter being improved by additivation. A wear scar diameter of $0.4 \mathrm{~mm}$ was measured for $\mathrm{F}=100 \mathrm{~N}$ and $0.55 \mathrm{~mm}$ for $\mathrm{F}=400 \mathrm{~N}$, when tested the vegetal oil at $1450 \mathrm{rpm}$, for 30 minutes.

Results obtained from tests done on the four ball machine are easy to be compared. Researchers could use the same set of test parameters for several lubricants and, based on obtained parameters, a rank of the investigated lubricants could be done.

The objective of this paper is to present sustainable results in the favor of using the rape seed oil as lubricant in systems that has to comply with environment protection regulations. The authors selected the fur ball tribotester as the results could be easier to be compared to other lubricant

\section{THE LUBRICANT AND THE TESTING METHODOLOGY}

The test parameters for were: loading force $-100 \mathrm{~N}$, $200 \mathrm{~N}$ and $300 \mathrm{~N}( \pm 5 \%)$, sliding speed of $0.38 \mathrm{~m} / \mathrm{s}$, $0.53 \mathrm{~m} / \mathrm{s}$ and $0.69 \mathrm{~m} / \mathrm{s}$, corresponding to the spindle speeds of the four-ball machine $1000 \mathrm{rpm}, 1400 \mathrm{rpm}$ and $1800 \mathrm{rpm}( \pm 6 \mathrm{rpm})$, respectively, test time -60 minutes $( \pm 1 \%)$. The test balls are lime polished, made of chrome alloyed steel balls (EN31), having $12.7 \pm 0.0005 \mathrm{~mm}$ in diameter, with $805 \mathrm{~N} / \mathrm{mm}^{2}$ hardness VHN, as delivered by SKF. The sample oil volume required for a test was $8 \mathrm{ml} \pm 1 \mathrm{ml}$. The composition in fatty acids of the rapeseed oil is given in Table 1.

Table 1. Typical composition in fatty acids of the rapeseed oil (from Expur Bucharest).

\begin{tabular}{ccc}
\hline Fat acid & Symbol & $\begin{array}{c}\text { Composition, } \\
\text { \%wt }\end{array}$ \\
\hline Myristic acid & C14:0 & 0.06 \\
Palmitic acid & C16:0 & 4.60 \\
Palmitoleic acid & C16:1 & 0.21 \\
Heptadecanoic acid & C17:0 & 0.07 \\
Heptadecenoic acid & C17:1 & 0.18 \\
Stearic acid & C18:0 & 1.49 \\
Oleic acid & C18:1 & 60.85 \\
Linoleic acid & C18:2 & 19.90 \\
Linolenic acid & C18:3 & 7.64 \\
Arachidic acid & C20:0 & 0.49 \\
Eicosenoic acid & $\mathrm{C} 20: 1$ & 1.14 \\
others & & 3.37 \\
\hline
\end{tabular}


Tests were one in laboratory atmosphere $\left(20 \ldots .23{ }^{\circ} \mathrm{C}\right.$ and $50 . . .60 \%$ relative humidity).

\section{RESULTS}

\subsection{The friction coefficient}

Figure 1 presents the records of friction coefficient for all the tests, the plots being obtained with a moving average of 200 samples (2 samples per second).

The friction coefficient has a repeatable evolution in time, except the most severe test $(\mathrm{F}=300 \mathrm{~N}, \mathrm{v}=0.69$ $\mathrm{m} / \mathrm{s}$ ), for which the differences are significant, meaning this parameter becomes difficult to be maintained under this regime.

It is important to point out that the evolution of $\mathrm{COF}$ has no significant peak, even in the first stage of friction (first 600...1000 s).

For $v=0.38 \mathrm{~m} / \mathrm{s}$ the average value of $\mathrm{COF}$ increases meaning that the fluid film tends to be destroyed due to the load increase, assuming that a mixt regime is characterizing this evolution.


Fig. 1. The evolution of friction coefficient 
For the other two tested sliding speeds, the values decrease for the highest load $(\mathrm{F}=300 \mathrm{~N})$, meaning that the increase in speed was beneficial for this tribological parameter. This could be argued based on the LHD theory [10] that says that the generation of a total fluid film is more influenced by the speed increase.

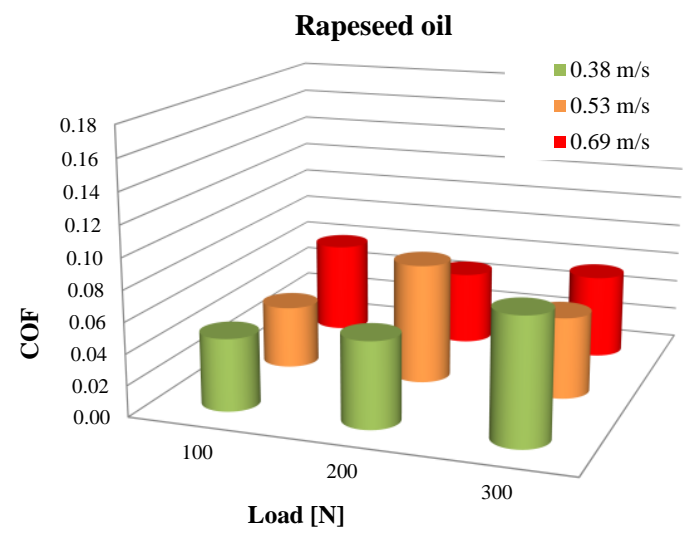

Fig. 2. The average of friction coefficient (COF) for two tests

\subsection{Wear parameter}

Measurement of wear trace diameters was done with an optical microscope, in accordance SR EN ISO 20623:2018 [11]. Three wear marks were obtained for each test, these being located on the three fixed balls. Two diameters, the first diameter measured along the sliding direction, the second diameter measured perpendicular to the first, were measured for each wear trace.

Table 2 gives the average value for WSD. The graphs of the wear scar diameters (WSD) as a function of speed could not reflect in a relevant way the influence of testing regimes, because all tests has $1 \mathrm{~h}$ (with different sliding distances for each speed), and, thus, the authors studied the influence of additive concentration with the help of wear rate of the scar diameter, noted by $w(W S D)$. The $w(W S D)$ is calculated with the help of the following relationship:

$$
w(W S D)=\frac{W S D}{F \times L}[\mathrm{~mm} /(N \cdot \mathrm{mm})]
$$

where $W S D$ is the average value of six measurements of the wear scar diameter, two on each fixed ball (one along the sliding direction and the other perpendicular to it), $\mathrm{F}$ is the load applied on the main shaft of the tribotester (carrying the rotating ball) and $\mathrm{L}$ is the sliding distance. The product $F \times L$ is the mechanical work done by the tribotester. Thus, the wear rate of WSD reflects the dimensional modification of WSD for the unit of mechanical work.

Figure 4 presents wear scars for the tested regimes. A qualitative analysis of these photos could conclude that $\mathrm{F}=300 \mathrm{~N}$ is a load towards the upper limit for this oil, as seizure and non-uniform wear are presented.

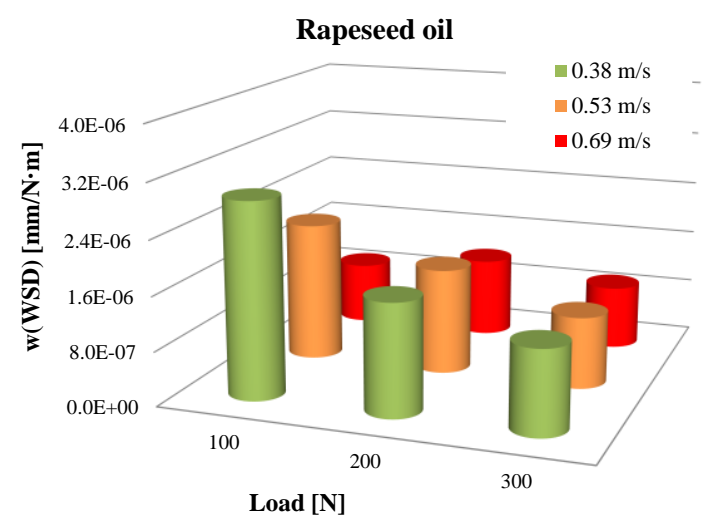

Fig. 3. Wear scar rate

Table 2. Values of WSD

\begin{tabular}{|c|c|c|c|c|c|}
\hline $\begin{array}{c}\mathbf{v} \\
{[\mathrm{m} / \mathrm{s}]}\end{array}$ & $\begin{array}{c}\mathbf{F} \\
{[\mathbf{N}]}\end{array}$ & 1 & 2 & 3 & Average \\
\hline \multirow{6}{*}{0.38} & \multirow{2}{*}{100} & 0.3964 & 0.4043 & 0.4353 & \multirow{2}{*}{0.3994} \\
\hline & & 0.3777 & 0.4014 & 0.3816 & \\
\hline & \multirow{2}{*}{200} & 0.4924 & 0.4714 & 0.5055 & \multirow{2}{*}{0.4583} \\
\hline & & 0.4239 & 0.4306 & 0.426 & \\
\hline & \multirow{2}{*}{300} & 0.5675 & 0.5689 & 0.5001 & \multirow{2}{*}{0.5159} \\
\hline & & 0.4963 & 0.4865 & 0.4766 & \\
\hline \multirow{6}{*}{0.53} & \multirow{2}{*}{100} & 0.4049 & 0.4102 & 0.4177 & \multirow{2}{*}{0.3999} \\
\hline & & 0.3771 & 0.3836 & 0.4062 & \\
\hline & \multirow{2}{*}{200} & 0.6634 & 0.6585 & 0.6441 & \multirow{2}{*}{0.6067} \\
\hline & & 0.5403 & 0.5722 & 0.5618 & \\
\hline & \multirow{2}{*}{300} & 0.6389 & 0.6719 & 0.6603 & \multirow{2}{*}{0.6178} \\
\hline & & 0.5807 & 0.5717 & 0.5835 & \\
\hline \multirow{6}{*}{0.69} & \multirow{2}{*}{100} & 0.2557 & 0.2347 & 0.2154 & \multirow{2}{*}{0.2307} \\
\hline & & 0.2492 & 0.2307 & 0.1988 & \\
\hline & \multirow{2}{*}{200} & 0.5957 & 0.5722 & 0.6019 & \multirow{2}{*}{0.5901} \\
\hline & & 0.5833 & 0.5861 & 0.6019 & \\
\hline & \multirow{2}{*}{300} & 0.7269 & 0.7269 & 0.7138 & \multirow{2}{*}{0.7045} \\
\hline & & 0.7057 & 0.6546 & 0.6991 & \\
\hline
\end{tabular}

\subsection{Temperature of the Oil Bath}

The temperature was measured by sinking a thermocouple with the range $0 . .200{ }^{\circ} \mathrm{C}$, after being calibrated in water + ice and boiling water.

At the same sliding speed, the highest temperature was recorded for the highest load $(\mathrm{F}=300$ $\mathrm{N})$. For the same sliding speed, the larger temperature interval for the values recorded at the end of the test was noticed for $\mathrm{v}=0.69 \mathrm{~m} / \mathrm{s}$. When increasing load from $\mathrm{F}=100 \mathrm{~N}$ to $\mathrm{F}=300 \mathrm{~N}$, the temperature in the oil bath increases with $25{ }^{\circ} \mathrm{C}$ for $\mathrm{v}=0.69 \mathrm{~m} / \mathrm{s}$ and only with $8 \ldots 9{ }^{\circ} \mathrm{C}$ for $\mathrm{v}=0.38 \mathrm{~m} / \mathrm{s}$. It is of interest to mentioned that for $\mathrm{F}=100 \mathrm{~N}$ the temperature was only $42 \ldots 45^{\circ} \mathrm{C}$ regardless the sliding speed. 

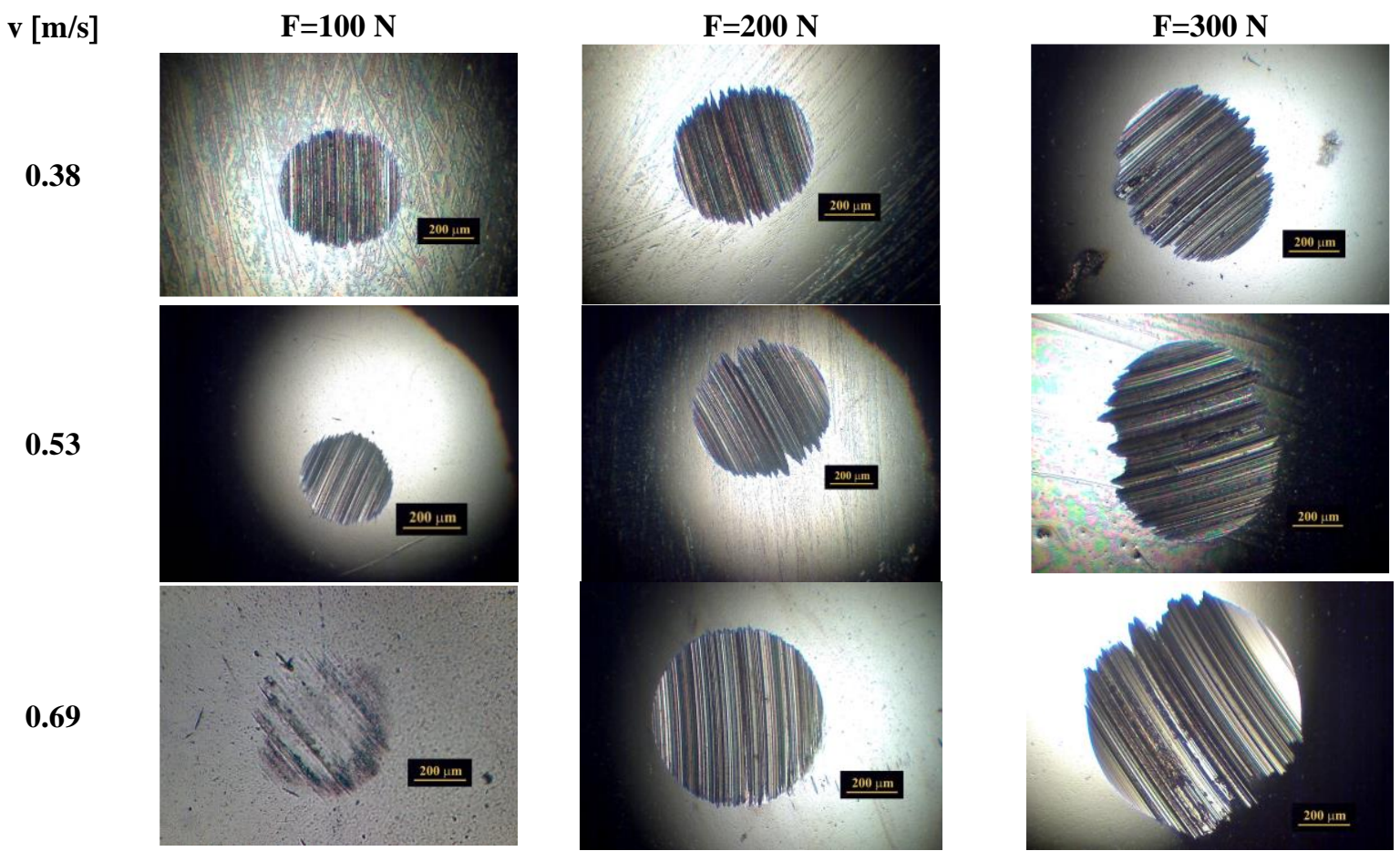

Fig. 4. Images of the wear scars
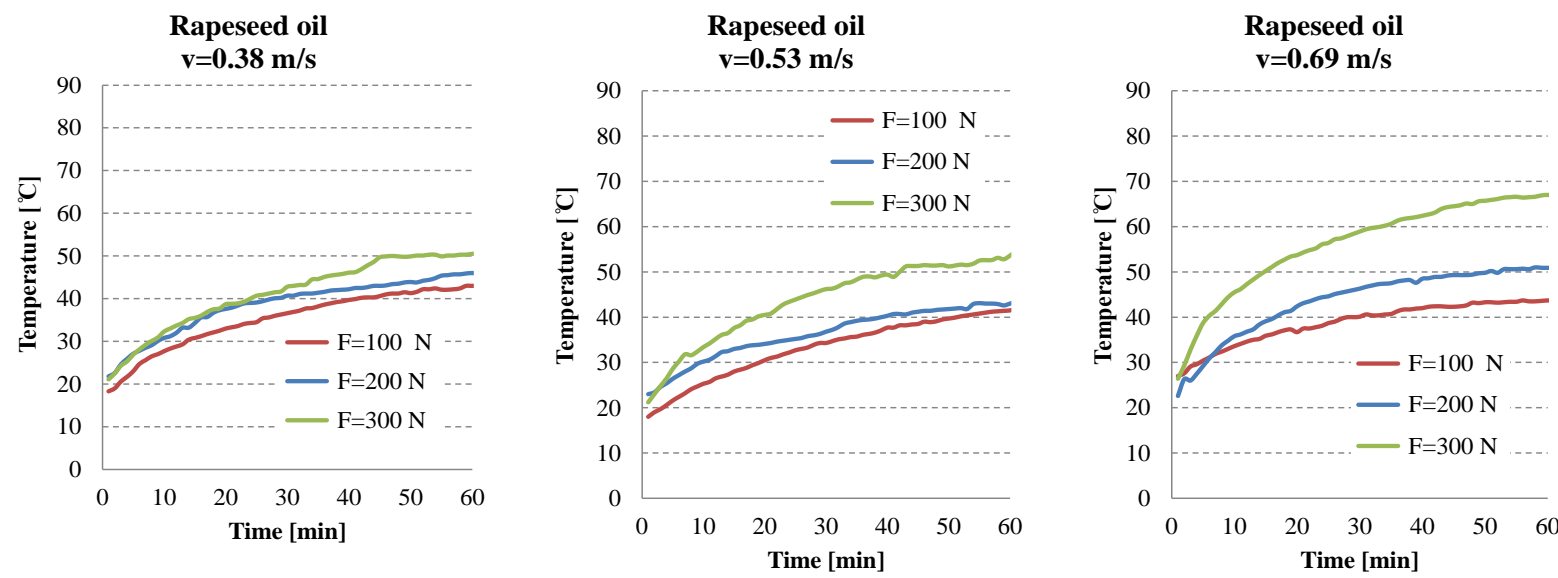

Fig. 5. Temperature evolution in time for the tested regimes

\section{CONCLUSIONS}

This paper presents the influence of test parameters on three tribological characteristics: friction coefficient, wear rate of the wear scar diameter and the temperature in the bath oil during 1 $h$ test for each set $(F, v)$.

Taking into account the obtained results, the following conclusions could be formulated.

For the tested regimes $(\mathrm{F}=100 \ldots 300 \mathrm{~N}$ and $\mathrm{v}=0.38 \ldots 0.69 \mathrm{~m} / \mathrm{s})$, the rapeseed oil could be recommended as lubricant because the friction coefficient is kept stable during the test (even from the beginning) and with values that indicate at least a fluid film lubricated regime (as all values are under 0.08).
The wear rate of wear scar diameter decreases when the load and speed increase, meaning an oil film protect the surface.

Temperature in the bath oil is still low (the highest being $69^{\circ} \mathrm{C}$ ) for not inducing chemical changes in the oil.

\section{ACKNOWLEGMENT}

This paper was supported by Doctoral School for Mechanical and Industrial Engineering of "Dunarea de Jos" University of Galati.

\section{REFERENCES}

[1] *** PHG, Reglementarea ,Uleiuri vegetale comestibile", 2010]. 
[2] Ştefănescu I., Şolea L. C., Chiriţă G., Ecological lubricants based on vegetal oils, The Annals of „Dunărea de Jos” University of Galati, Fascicle VIII, Tribology, (XVII), Issue 1, Galati University Press, pp. 110-117, 2011.

[3] Șolea L. C., On the lubrication capability of rapeseed oil, Proceedings of the $6^{\text {th }}$ International Conference on Mechanics and Materials in Design, 2015, P Delgada/ Azores, Portugal, paper ref: 5533.

[4] Penciu S.: Studiul potențialului de export al României: Uleiuri vegetale, Centrul Român pentru Promovarea Comerțului și Investițiilor Străine, 2012.

[5] Yang M., Zheng C., Zhou Q., Huang F., Liu C., Wang H., Minor components and oxidative stability of cold-pressed oil from rapeseed cultivars in China, Journal of Food Composition and Analysis, 29(1), 2013, pp. 1-9

[6] Naczk M., Recovery of rapeseed tannins by various solvent systems, Food Chemistry, 45, 1992, pp. 51-54.
[7] Ruggiero A., D’Amato R., Merola M., Valašek P., Müller M., Experimental analysis of tribological properties of biolubricant with nanoparticle additive, Procedia Engineering 68, 2017, pp: 152-157.

[8] Gu K., Chen B., Wang X., Wang J., Fang J., Wu J., Huang L., Preparation, friction and wear properties of hydrophobic lanthanum borate nanorods in rapeseed oil, Transactions of Nonferrous Met. Soc. China 24, 2014, pp. 3578-3584.

[9] Li Z., Ren T., Synergistic effects between alkylphosphate-ammonium ionic liquid and alkylphenylborate as lubricant additives in rapeseed oil, Tribology International 109, 2017, pp. 373-381.

[10]Dowson D., Higginson G. R., Elastohydrodynamic lubrication, Oxford, Pergamon Press, 1977.

[11] SR EN ISO 20623: 2018 Petroleum and related products. Determination of the extreme-pressure and anti-wear properties of lubricants. Four-ball method (European conditions). 